\title{
Especialidades Médicas - Medicina Legal e Perícias Médicas
}

\author{
Daniel Romero Muñoz', Victor Gianvecchio, Ivan Miziara
}

\section{Introdução}

A Medicina Legal é uma das mais antigas especialidades médicas. Ela nasceu, oficial e legalmente, em 1507 na Alemanha, com a promulgação do Código de Bamberg, que determinava a atuação de médicos em processos judiciais'.

Segundo o professor Flamínio Fávero, médico formado pela primeira turma (1913-1919) da Faculdade de Medicina e Cirurgia de São Paulo e Catedrático de Medicina Legal, a Medicina Legal age e deve agir pela "aplicação dos conhecimentos médico-biológicos na elaboração e execução das leis que deles carecem"2.

Em outras palavras, a Medicina Legal é a área de sobreposição entre a Medicina e o Direito; seu campo de atuação abrange as perícias médicas, sejam elas judiciais ou extra judiciais (administrativas lato senso) $)^{1}$.

\section{Mitos e panorama atual da especialidade}

No Brasil, dentro da própria classe médica, a Medicina Legal foi vista por muito tempo como a especialidade que "cuida de cadáveres".

Esta visão distorcida certamente acarretou, ao longo de anos, a baixa procura pela formação acadêmica na especialidade, apesar de muitos médicos trabalharem realizando perícias médicas sem saber que estão exercendo Medicina Legal, por exemplo, como peritos do INSS.
Felizmente este panorama começou a se modificar com a implantação da Residência Médica em Medicina Legal na FMUSP em 2004, e vem se modificando cada vez mais com a crescente procura de médicos por adequada formação acadêmica na área através de Cursos de Especialização (Pósgraduação lato senso).

Além disso, a especialidade está vivendo atualmente um momento de grande relevância histórica com a recente mudança do nome para "Medicina Legal e Perícias Médicas" (Resolução CFM 1973/2011) e a união das duas entidades que congregam médicos peritos, a Associação Brasileira de Medicina Legal e a Sociedade Brasileira de Perícias Médicas, formando a Associação Brasileira de Medicina Legal e Perícias Médicas.

\section{Formação acadêmica em medicina legal e perícias médicas $^{4}$}

A formação de um especialista em Medicina Legal e Perícias Médicas exige conhecimentos médicos gerais amplos e noções de Direito.

Além disso, o aluno que irá se especializar nesta área deve aprender e dominar os critérios médico-legais específicos de cada situação pericial, os quais estabelecem a ligação entre os parâmetros médicos (diagnósticos, terapêuticos e preventivos) e os jurídicos.

O único Programa de Residência Médica em Medicina Legal e Perícias Médicas do Brasil é o da

Graduação em Medicina pela Faculdade de Ciências Médicas de Santos - 1973, Mestrado em Patologia Experimental e Comparada pela USP - 1983, Doutorado em Patologia USP - 1987, Livre-docência pela FMUSP, Professor titular de Medicina Legal, Medicina do Trabalho e Bioética da FMUSP. 
Faculdade de Medicina da Universidade de São Paulo (FMUSP), que começou a ser desenvolvido em 2004. O programa tem a duração de três anos e duas vagas por ano credenciadas pela Comissão Nacional de Residência Médica.

A primeira etapa da residência é centrada na formação médica geral, e é realizada no Hospital das Clínicas da FMUSP (HC-FMUSP), onde o residente realiza estágios em cinco grandes áreas da medicina, junto com os residentes de cada serviço: Clínica Médica (pronto socorro geral, pronto socorro cardiológico, UTI e ambulatórios de clínica médica geral, cardiologia, pneumologia, reumatologia e neurologia), Clínica Cirúrgica (pronto socorro de trauma, ortopedia, serviço de anestesiologia e ambulatórios de neurocirurgia, ortopedia, cirurgia plástica, urologia, coloproctologia, oftalmologia e otorrinolaringologia), Ginecologia e Obstetrícia (sala de parto, pronto socorro e ambulatórios), Pediatria (pronto socorro e berçário) e Psiquiatria (pronto socorro e ambulatórios). Além disso, o residente de Medicina Legal e Perícias Médicas realiza estágios de Medicina do Trabalho (Serviço de Saúde Ocupacional do HCFMUSP e ambulatório médico de uma grande empresa em São Paulo), Medicina Física e Reabilitação e Patologia.

A segunda etapa é centrada na formação pericial específica, e é composta de estágios onde o residente realiza perícias cíveis (Instituto de Medicina Social e Criminologia de São Paulo - IMESC), perícias criminais (Instituto Médico Legal - IML), perícias de acidentes do trabalho (Divisão de Perícias do Tribunal de Justiça de São Paulo), perícias previdenciárias (Setor de Perícias do Juizado Especial Federal) e perícias administrativas (Departamento de Perícias Médicas do Estado de São Paulo - DPME).

Todos os "ex-residentes" que se submeteram ao concurso público para a carreira de Médico Legista no Estado de São Paulo foram aprovados. Além disso, a maioria vem atuando também como Peritos Judiciais ou como Assistentes Técnicos, e dois estão trabalhando na iniciativa privada, em uma grande empresa seguradora, na cidade de São Paulo (perícias securitárias).

O curso de Especialização em Medicina Legal e Perícias Médicas vem sendo a opção da maioria dos médicos que já possuem uma especialidade e desejam realizar perícias médicas utilizando conhecimentos específicos de sua especialidade, e para tanto necessitam aperfeiçoar seus conhecimentos em Medicina Legal e Perícias Médicas.

\section{Mercado de trabalho do médico especialista em medicina legal e perícias médicas}

Como visto acima, a Medicina Legal e Perícias Médicas, apesar de ser uma especialidade médica, não visa tratar ou prevenir doenças; como área de intersecção entre a Medicina e o Direito, seu objetivo é a justiça: - É a contribuição da Medicina para o estabelecimento da justiça social. Desse modo, o médico que a exerce tem um papel fundamental na preservação dos direitos do ser humano ${ }^{4}$.

Na prática, o médico perito atua fornecendo a prova técnica de natureza médica, ou seja, perícia médica na qual realiza investigações próprias da ciência médica (exames clínico, laboratorial, necroscópico e outros, tais como vistoria de local), para esclarecer fatos que interessam em um processo judicial (processo civil, criminal, trabalhista, etc.) ou em um procedimento administrativo (sindicância, por exemplo $)^{4}$.

De acordo com o Código de Processo Civil, sempre que a prova do fato depender de conhecimento técnico ou científico, o Juiz será assistido por perito. O médico indicado pelo Juiz para atuar nesse tipo de processo (civil, trabalhista etc.) é denominado perito judicial ${ }^{5}$.

O Código de Processo Civil prevê também que cada uma das partes pode indicar assistente técni$\mathrm{co}^{5}$. Em outras palavras, esse tipo de perícia pode se constituir em uma verdadeira junta médica, uma vez que o juiz, além de indicar um médico de sua confiança (perito judicial), nomeia, como assistentes técnicos, os médicos indicados pelas partes envolvidas nesse processo. Isto ocorre tanto nas varas cíveis estaduais como nas federais, nas varas de acidentes do trabalho, nas varas trabalhistas, no Juizado Especial Federal e em outras instâncias jurídicas.

Os honorários do perito judicial será estabelecido pelo juiz, entretanto, para alguns tipos de perícia, existem normativas sobre os honorários dos médicos peritos. Nas perícias de acidente do trabalho, por exemplo, a Portaria que se encontra em vigor atualmente estabelece que o valor dos honorários para cada perícia é de $R \$ 385,00$, para cada inspeção judicial é de $R \$ 235,00$ e para a Vistoria no Local de Trabalho é de $\mathrm{R} \$ 533,00^{6}$.

O assistente técnico, por outro lado, atua de forma autônoma, contratado por uma das partes que estão litigando no processo. Como profissional autônomo, ele estabelece seus honorários.

Outra possibilidade para o Especialista em Medicina Legal e Perícias Médicas é atuar como 
perito oficial. Perito oficial é aquele que foi habilitado em concurso público para exercer suas atribuições em uma instituição pública ${ }^{7}$.

No Processo Criminal, conforme o Código de Processo Penal, o exame de corpo de delito e outras perícias são realizados por perito oficial ${ }^{8}$. Ou seja, para realizar perícia criminal, o médico deve ser perito oficial concursado.

O nome dessa carreira pública dos Estados é Médico Legista, e a remuneração varia de Estado para Estado. Em São Paulo, segundo o edital do último concurso público (ML 1/2011), os vencimentos iniciais da carreira eram de $R \$ 6.169,30^{9}$.

O corpo de médicos peritos do Instituto Nacional do Seguro Social (INSS) e dos Departamentos Médicos da União, Estados e Municípios também é formado por peritos oficiais, concursados. No INSS, segundo o edital do último concurso para Perito Médico Previdenciário, a remuneração inicial da carreira totalizava $\mathrm{R} \$ 9.070,93^{10}$.

Existe ainda mercado de trabalho para o médico especialista nesta área na iniciativa privada. Diversas empresas seguradoras possuem, em seu quadro de funcionários, médicos contratados para atuar, como peritos, nos processos administrativos (internos) em que um segurado solicita o prêmio de um seguro contratado.

Finalmente, vale destacar que a Medicina Legal é disciplina obrigatória nas faculdades de medicina, está inserida na grade curricular de muitas da faculdade de direito e faz parte das matérias cobradas em diversos concursos públicos da área jurídica. Desse modo, a carreira docente em nível universitário (graduação e pós-graduação) é, também, uma opção de trabalho para o médico especializado em Medicina Legal e Perícias Médicas.

\section{REFERÊNCIAS}

1. Muñoz DR, Muñoz-Gianvecchio D, Gianvecchio VAP. Momento histórico de uma especialidade. Saúde Ética Justiça. 2010;15(2):69-74.

2. Fávero F. Medicina legal. São Paulo: Martins; 1973.

3. Brasil. Conselho Federal de Medicina. Resolução 1.973/2011. Disponível em: http://www.portalmedico. org.br/resolucoes/CFM/2011/1973_2011.htm.

4. Muñoz DR, Gianvecchio VAP. Residência médica em medicina legal: objetivos. Saúde Ética Justiça. 2005;10(1/2):6-11.

5. Brasil. Lei $n^{\circ} 5.869$ de 11 de janeiro de 1973. Institui o Código de Processo Civil. Disponível em: http://www. planalto.gov.br/ccivil_03/Leis/L5869.htm

6. Portaria Conjunta $n^{\circ} 02 / 2008$ dos Juízes de Direito das Varas de Acidente do Trabalho da Comarca da Capital.

7. Hercules HC. Medicina legal - texto e atlas. São Paulo: Atheneu; 2008.

8. Brasil. Decreto-Lei no 3.689, de 3 de outubro de 1941. Código de Processo Penal. Disponível em: http://www. planalto.gov.br/ccivil_03/Decreto-Lei/Del3689.htm

9. http://www2.policiacivil.sp.gov.br/x2016/uploads_outros/arquivos/20111229025114_4efc9a82cc394_.pdf.

10. http://www.concursosfcc.com.br/concursos/inssd111/ edital_16_12_dou.pdf. 